11

\title{
Частотная зависимость коэффициента поглощения электромагнитного излучения в магнитной жидкости
}

\author{
(C) К.Г. Гареев, В.В. Лучинин, Е.Н. Севостьянов, И.О. Тестов, О.А. Тестов \\ Санкт-Петербургский государственный электротехнический университет „ЛЭТИ“, \\ 197376 Санкт-Петербург, Россия \\ e-mail: kggareev@yandex.ru
}

Поступило в Редакцию 5 сентября 2018г.

В окончательной редакции 12 ноября 2018г.

Принято к публикации 21 декабря 2018г.

Получены образцы магнитной жидкости на водной основе, содержащие частицы $\mathrm{Fe}_{3} \mathrm{O}_{4}-\mathrm{SiO}_{2}$ сферической формы размерами менее $100 \mathrm{~nm}$. Методом, основанным на использовании линии передачи, проведены измерения коэффициента поглощения электромагнитного излучения в диапазоне частот $0.1-18.0 \mathrm{GHz} \mathrm{c}$ использованием измерительного стенда на основе рупорных антенн и ячейки на основе копланарной линии передачи. Установлена возможность использования магнитных жидкостей для создания электромагнитных экранов и поглотителей электромагнитных волн, а также как средства для проведения локальной гипертермии при частотах электромагнитного излучения свыше $7 \mathrm{GHz}$.

DOI: 10.21883/JTF.2019.06.47645.331-18

\section{Введение}

Магнитные жидкости на водной основе используются в качестве средства тераностики - направления медицины, сочетающего в себе диагностику и терапию. Для тераностики актуальна задача повышения контраста при диагностике (например, методом магниторезонансной томографии). Одно из решений связано с использованием магнитных наночастиц, имеющих низкую токсичность, например, частиц магнетита-кремнезема $\left(\mathrm{Fe}_{3} \mathrm{O}_{4}-\mathrm{SiO}_{2}\right)$, повышающих контраст [1] за счет наличия суперпарамагнитных свойств $[2,3]$ и обеспечивающих высокую агрегативную устойчивость [4] и возможность локального изменения их концентрации при воздействии внешнего магнитного поля [5]. Биосовместимость частиц $\mathrm{Fe}_{3} \mathrm{O}_{4}-\mathrm{SiO}_{2}$ подтверждена испытаниями, проведенными на культурах клеток [6] и на лабораторных животных [7]. На основании полученных результатов и патентных исследований предложенный способ получения магнитной жидкости был защищен патентом [8].

Другое актуальное применение магнитных жидкостей в медицине относится к их использованию в качестве средства локальной гипертермии. Эффективность локального разогрева биологических тканей магнитными частицами зависит от коэффициента поглощения ими электромагнитного излучения.

Взаимодействие магнитных жидкостей с электромагнитным излучением может использоваться при создании высокоэффективных электромагнитных экранов и поглотителей электромагнитных волн, предназначенных для защиты биологических и технических объектов [9], что объясняется высокими значениями магнитных потерь [10].

Настоящая работа посвящена исследованию частотных зависимостей коэффициента поглощения электро- магнитного излучения в диапазоне $0.1-18.0 \mathrm{GHz}$ магнитной жидкостью на основе частиц $\mathrm{Fe}_{3} \mathrm{O}_{4}-\mathrm{SiO}_{2}$.

\section{Материал и методы исследования}

Измерения частотных зависимостей коэффициента поглощения проводились на образцах магнитной жидкости, полученных в соответствии со способом, описанным в патенте [8]. Магнитная жидкость изготавливалась на водной основе при массовой концентрации магнитных частиц $30 \mathrm{~g} / 1$ (3 wt.\%).

Форма и размеры частиц $\mathrm{Fe}_{3} \mathrm{O}_{4}-\mathrm{SiO}_{2}$ исследовались методами атомно-силовой микроскопии при помощи сканирующего зондового микроскопа Veeco Dimension 3100 (Veeco Instruments Inc., США) и динамического рассеяния света с использованием прибора Фотокор Мини (ООО „Фотокор“, Россия).

Коэффициент поглощения электромагнитного излучения в диапазоне $0.1-18.0 \mathrm{GHz}$ измерялся методом, основанным на использовании линии передачи [11]. Такой метод характеризуется погрешностью порядка 10\% [12].

Генерация и детектирование электромагнитных волн осуществлялись векторным анализатором цепей ZVB-20 (Rhode \& Schwarz, Германия) с рабочим частотным диапазоном от $10 \mathrm{MHz}$ до $20 \mathrm{GHz}$.

Измерения коэффициента поглощения в частотном диапазоне $2.0-18.0 \mathrm{GHz}$ проводились при помощи портативного закрытого измерительного стенда на основе рупорных антенн П6-124 (ЗАО „СКАРД-Электроникс“, Россия), принцип действия которого описан в [13]. На рис. 1 приведены изображения общего вида стенда и положение образца размерами $170 \times 170 \times 6 \mathrm{~mm}$ (объем магнитной жидкости $200 \mathrm{ml}$ ) при выполнении измерений. 

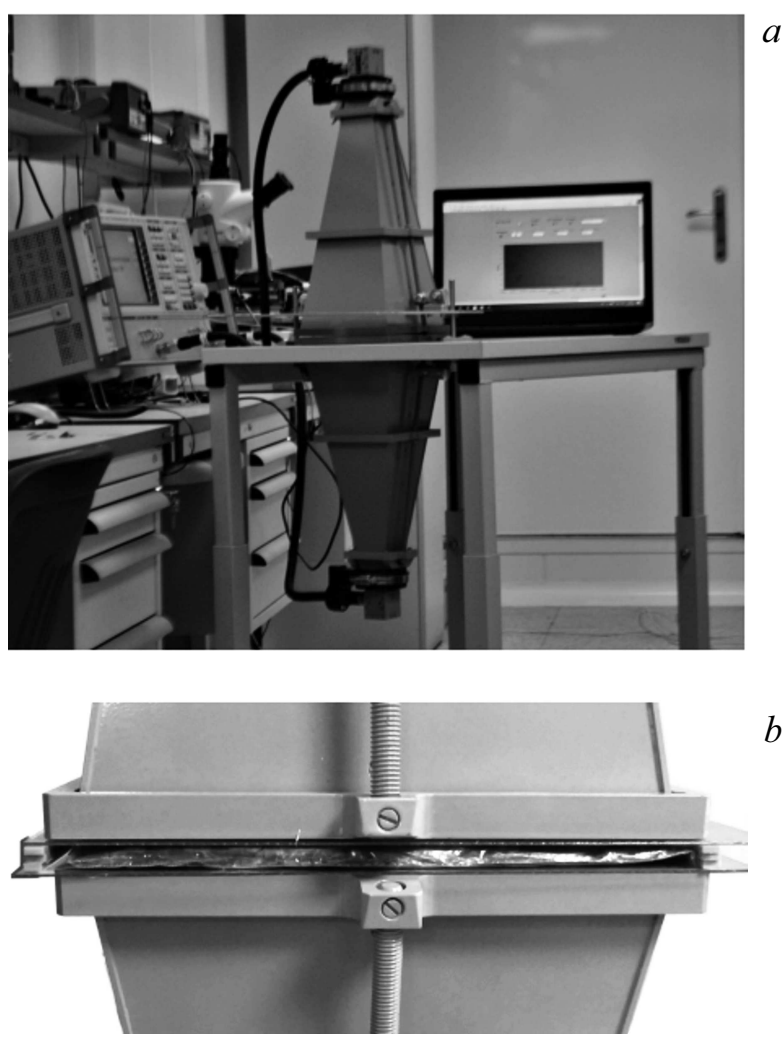

Рис. 1. Измерительный стенд на основе рупорных антенн: $a$ - общий вид; $b-$ положение образца при проведении измерений.
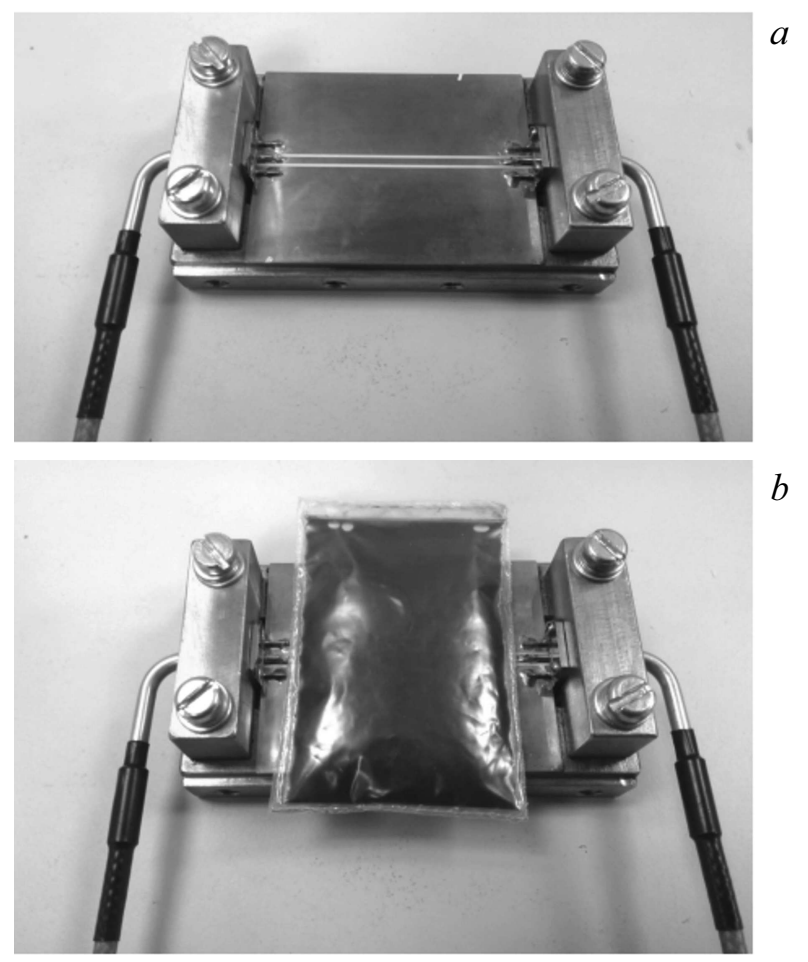

Рис. 2. Внешний вид ячейки на основе копланарной линии передачи: $a-$ без образца; $b-$ с образцом.
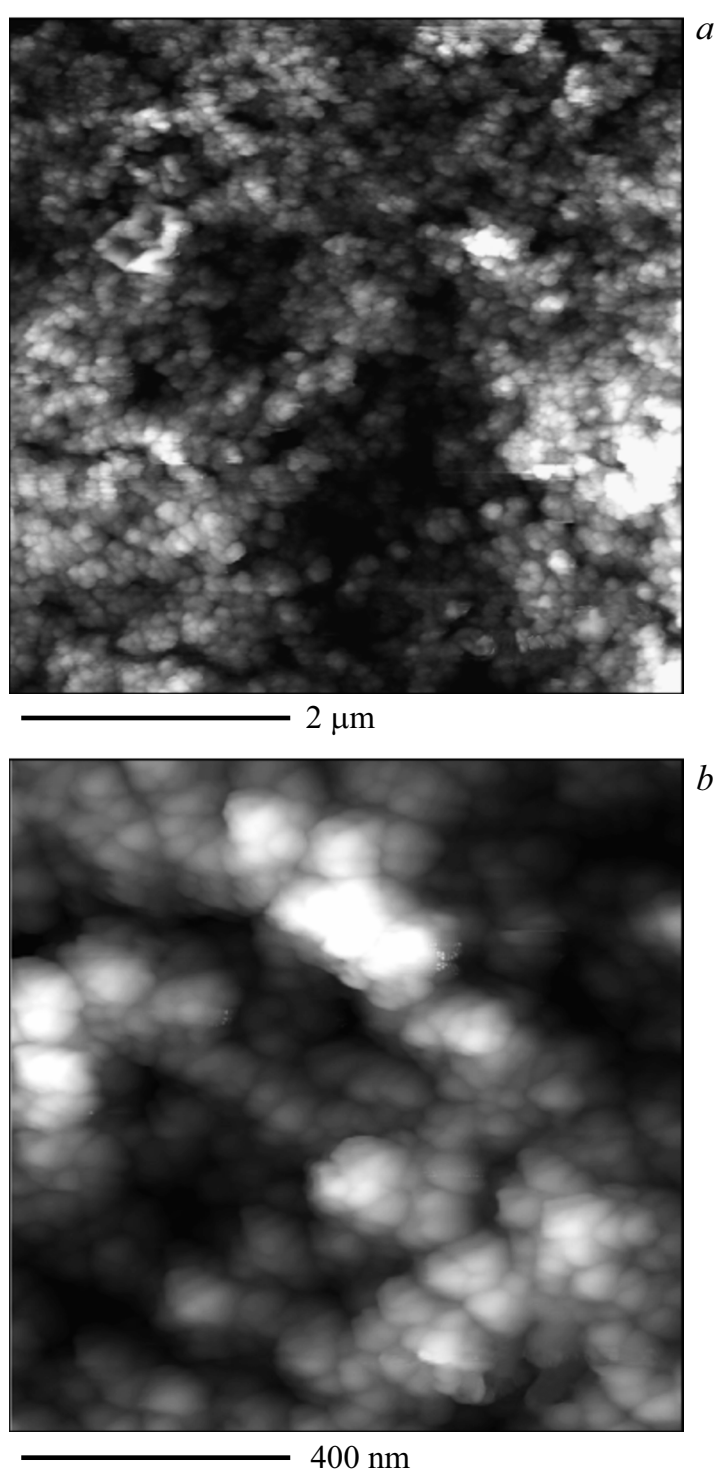

Рис. 3. Атомно-силовые изображения осадка, полученного высушиванием магнитной жидкости: $a-$ размер изображения $5 \times 5 \mu \mathrm{m} ; b-$ размер изображения $1 \times 1 \mu \mathrm{m}$.

В диапазоне частот порядка $0.1 \mathrm{GHz}$ рупорные антенны применять нецелесообразно в связи с их большими геометрическими размерами, требующими значительного расхода материала при подготовке образцов. В связи с этим коэффициент поглощения в диапазоне частот $0.1-2.0 \mathrm{GHz}$ измерялся при помощи ячейки на основе копланарной линии передачи (рис. 2,a) с волновым сопротивлением $50 \Omega$. Образец магнитной жидкости в объеме $10 \mathrm{ml}$ герметизировался в оболочке из полиэтилена размерами $60 \times 40 \mathrm{~mm}$ (рис. $2, b)$.

Коэффициент поглощения $L$ в процентах рассчитывался по формуле

$$
L=\left(1-\left|S_{21}\right|^{2}-\left|S_{11}\right|^{2}\right) \cdot 100,
$$

где $\left|S_{21}\right|$ и $\left|S_{11}\right|$ - модули комплексных коэффициентов рассеяния. 


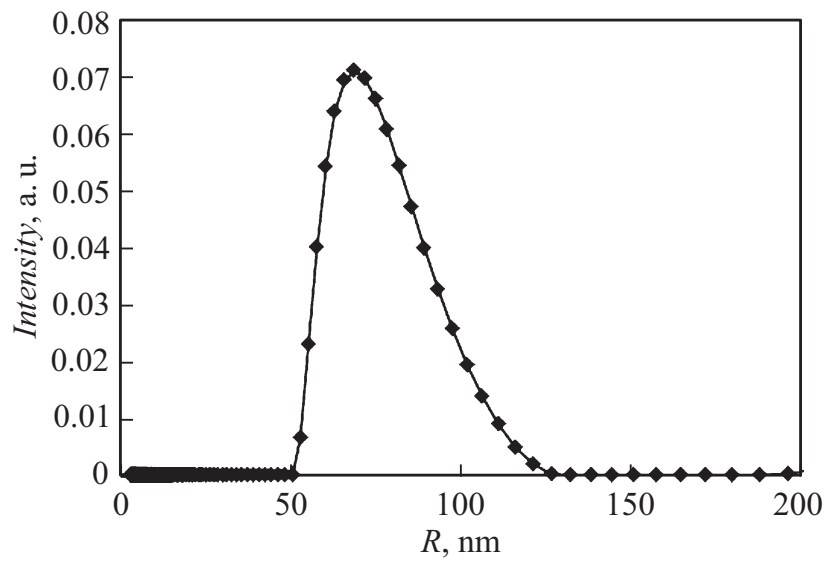

Рис. 4. Распределение частиц магнитной жидкости по радиусу, полученное методом динамического рассеяния света.
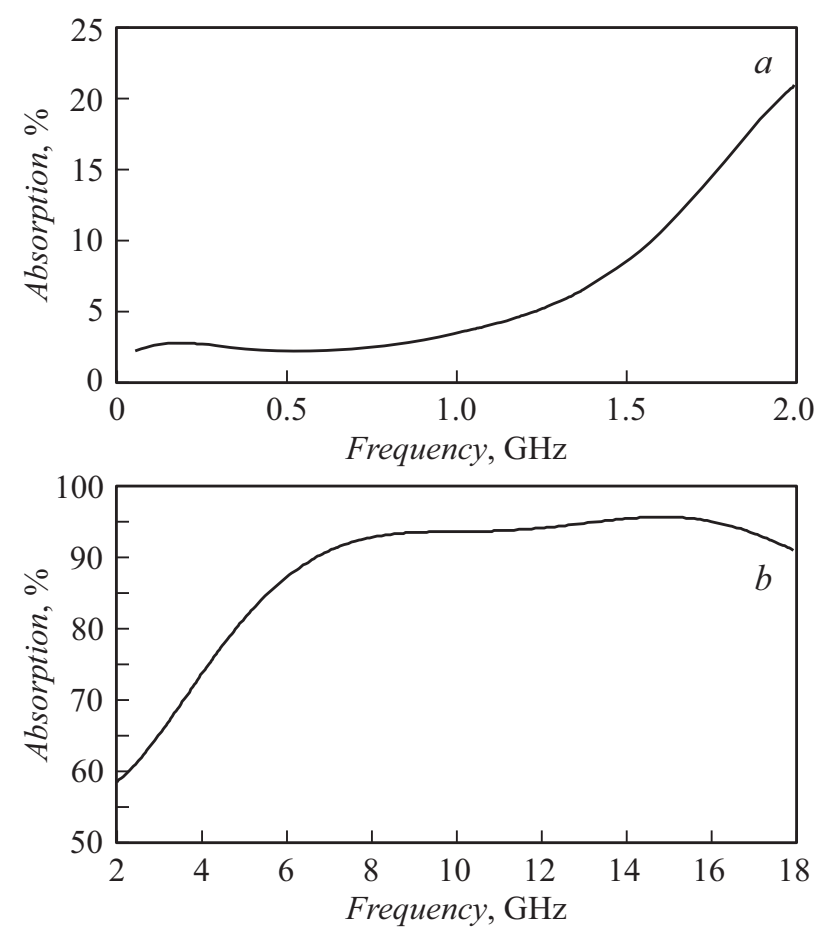

Рис. 5. Частотные зависимости коэффициента поглощения магнитной жидкости: $a-$ полученные с использованием ячейки на основе копланарной линии передачи; $b$ - полученные с использованием стенда на основе рупорных антенн.

\section{Результаты исследования}

Атомно-силовые изображения поверхностей, полученных при удалении (высушивании) дисперсионной среды, приведены на рис. 3. После разбавления магнитной жидкости в 200 раз методом динамического рассеяния света исследовалось распределение частиц по радиусу (рис. 4).

Рис. 3 и 4 показывают, что форма частиц в магнитной жидкости близка к сферической, а средний радиус частиц составляет менее $100 \mathrm{~nm}$.
Частотные зависимости коэффициента поглощения, полученные с использованием ячейки на основе копланарной линии передачи и стенда на основе рупорных антенн, приведены на рис. 5, $a$ и $b$ соответственно. Как видно из полученных зависимостей, коэффициент поглощения электромагнитного излучения на частоте $2 \mathrm{GHz}$, полученный с использованием копланарной линии передачи, примерно втрое ниже значения, полученного при помощи стенда на основе рупорных антенн. Данное различие обусловлено наличием между магнитной жидкостью и поверхностью копланарной линии передачи двуслойной оболочки толщиной порядка $0.1 \mathrm{~mm}$, не оказывающей влияние на затухание электромагнитной волны. Для выбранного метода измерений такая толщина существенно снижает значение коэффициента поглощения, что связано с тем, что возбуждаемая в линии передачи квази-Т электромагнитная волна распространяется внутрь образца на глубину менее $1 \mathrm{~mm}$ [14]. Тем не менее такой метод достаточно чувствителен, что позволяет использовать его для сравнительного анализа образцов различных материалов.

Исследования показали, что при толщине слоя магнитной жидкости, равной $6 \mathrm{~mm}$, коэффициент поглощения электромагнитного излучения частотой свыше $7 \mathrm{GHz}$ составляет не менее $90 \%$, что актуально для использования при локальной гипертермии. Увеличение коэффициента поглощения с ростом частоты может быть объяснено возрастанием магнитных потерь (мнимой компоненты магнитной восприимчивости) в частицах магнетита [10].

\section{Заключение}

Установлено, что в диапазоне частот $0.1-18.0 \mathrm{GHz}$ коэффициент поглощения электромагнитного излучения полученных материалов изменяется от 2 до $95 \%$.

Результаты свидетельствуют о возможности применения магнитной жидкости на основе частиц $\mathrm{Fe}_{3} \mathrm{O}_{4}-\mathrm{SiO}_{2}$ при производстве композитных экранов и поглотителей электромагнитных волн, обладающих конформными свойствами. Конструкции таких изделий могут быть реализованы на основе обработанных магнитной жидкостью текстильных материалов.

\section{Финансирование работы}

Работа частично поддержана грантом РФФИ, проект № 16-32-60010.

\section{Список литературы}

[1] Bogachev Yu.V., Chernenco Ju.S., Gareev K.G., Kononova I.E., Matyushkin L.B., Moshnikov V.A., Nalimova S.S. // Appl. Magn. Reson. 2014. Vol. 45. N 3. P. 329-337. DOI: $10.1007 / \mathrm{s} 00723-014-0525-7$

[2] Kharitonskii P.V., Gareev K.G., Ionin S.A., Ryzhov V.A., Bogachev Yu.V., Klimenkov B.D., Kononova I.E., Moshnikov V.A. // J. Magnetics. 2015. Vol. 20. N 3. P. 221-228. DOI: 10.4283/JMAG.2015.20.3.221 
[3] Kharitonskii P., Kamzin A., Gareev K., Valiullin A., Vezo O., Sergienko E., Korolev D., Kosterov A., Lebedev S., Gurylev A., Reinyuk A. // J. Magn. Magn. Mater. 2018. Vol. 461. P. 30-36. DOI: 10.1016/j.jmmm.2018.04.044

[4] Везо О.С., Гареев К.Г., Королев Д.В., Курышев И.А., Лебедев С.В., Мошников В.А., Сергиенко Е.С., Харитонский П.В. // ФТТ. 2017. Т. 59. Вып. 5. С. 980-985. [Vezo O.S., Gareev K.G., Korolev D.V., Kuryshev I.A., Lebedev S.V., Moshnikov V.A., Sergienko E.S., Kharitonskii P.V. // Phys. Sol. State. 2017. Vol. 59. N 5. P. 1008-1013.]

DOI: $10.1134 / \mathrm{S} 1063783417050304$

[5] Кононова И.Е., Гареев К.Г., Мошников В.А., Альмяшев В.И., Кучерова О.В. // Неорган. материалы. 2014. T. 50. Вып. 1. С. 75-81. [Kononova I.E., Gareev K.G., Moshnikov V.A., Al'myashev V.I., Kucherova O.V. // Inorg. Mater. 2014. Vol. 50. N 1. P. 68-74.]

DOI: $10.1134 / \mathrm{S} 0020168514010117$

[6] Toropova Y.G., Golovkin A.S., Malashicheva A.B., Korolev D.V., Gorshkov A.N., Gareev K.G., Afonin M.V., Galagudza M.M. // Int. J. Nanomed. 2017. Vol. 12. P. 593-603. DOI: $10.2147 / \mathrm{IJN} . S 122580$

[7] Торопова Я.Г., Зелинская И.А., Маркитантова А.С., Печникова Н.А., Чебу С.Г., Королев Д.В., Гареев К.Г., Поволоцкая А.В., Маньшина А.А. // Рос. физиол. журн. им. И.М. Сеченова. 2017. Т. 103. Вып. 12. С. 1416-1424.

[8] Гареев К.Г., Рейнюк А.В., Тестов Д.О., Лучинин В.В., Мошников В.А. Патент РФ № 2639709. 2017. БИ. № 36.

[9] Alam J., Riaz U., Ahmad S. // J. Magn. Magn. Mater. 2007. Vol. 314. N 2. P. 93-99. DOI: 10.1016/j.jmmm.2007.02.195

[10] Oda S., Kitamoto Y. // AIP Adv. 2017. Vol. 7. P. 056729. DOI: $10.1063 / 1.4977973$

[11] Харвей А.Ф. Техника сверхвысоких частот / Под ред. В.И. Сушкевича. М.: Сов. радио, 1965. С. 312.

[12] Ritzmann D., Wright P.S., Holderbaum W., Potter B. // IEEE Tr. Instrum. Meas. 2016. Vol. 65. P. 2204-2213. DOI: 10.1109/TIM.2016.2556920

[13] Андрющенко М.С., Гусаковский В.Е., Штагер Е.А., Штагер Д.Е., Щесняк С.C. Методы расчета средств защиты радиоэлектронных систем от электромагнитного излучения / Под ред. С.С. Щесняка. СПб: ВВМ, 2016. С. 271-273.

[14] Бахарев С.И., Вольман В.И., Либ Ю.Н., Мамонова Н.М., Муравцов А.Д., Саркисьяни, А.Г., Силин Р.А., Славинский О.К., Ширяев Д.Д. Справочник по расчету и конструированию СВЧ полосковых устройств. / Под ред. В.И. Вольмана. М.: Радио и связь, 1982. С. 81. 